\title{
(6) OPEN ACCESS \\ Predictors of patient satisfaction in an emergency care centre in central Saudi Arabia: a prospective study
}

\author{
Mostafa A Abolfotouh, ${ }^{1,2}$ Mohammed H Al-Assiri, ${ }^{1}$ Rabab T Alshahrani, ${ }^{2}$ \\ Zainab M Almutairi, ${ }^{1}$ Raid A Hijazi, ${ }^{3}$ Ahmed S Alaskar ${ }^{1,4}$
}

${ }^{1}$ King Abdullah International Medical Research Center, King Saud Bin-Abdulaziz University for Health Sciences, Riyadh, Saudi Arabia

${ }^{2}$ College of Medicine, King Saud bin Abdulaziz University for Health Sciences, Riyadh, Saudi Arabia

${ }^{3}$ Emergency Care Center, King Saud University, College of Medicine, Riyadh, Saudi Arabia ${ }^{4}$ Department of Oncology, King Abdulaziz Medical City, Ministry of National Guard Health Affairs, Riyadh, Saudi Arabia

\section{Correspondence to} Professor Mostafa A Abolfotouh, King Abdullah International Medical Research Center (Mail Code 1515), King Saud bin Abdulaziz University for Health Sciences (KSAU-HS), Ministry of National GuardHealth Affairs, P.O. Box 22490, Riyadh 11426, Saudi Arabia;

mabolfotouh@gmail.com

This work was presented at the 3rd Research Summer School programme of KAIMRC.

Received 20 April 2015 Revised 20 June 2016 Accepted 8 July 2016 Published Online First 1 August 2016

\section{CSLinked}

- http://dx.doi.org/10.1136/ emermed-2016-206289

\section{CrossMark}

To cite: Abolfotouh MA Al-Assiri MH, Alshahrani RT, et al. Emerg Med J 2017;34:27-33.

\section{ABSTRACT}

Aim This study aimed to (i) assess the level of patient satisfaction and its association with different sociodemographic and healthcare characteristics in an emergency care centre (ECC) in Saudi Arabia and (ii) to identify the predictors of patients' satisfaction.

Methods A prospective cohort study of 390 adult patients with Canadian triage category III and IV who visited ECC at King Abdulaziz Medical City, Riyadh, Saudi Arabia, between 1 July and end of September 2011 was conducted. All patients were followed up from the time of arrival at the front desk of ECC until being seen by a doctor, and were then interviewed. Patient satisfaction was measured using a previously validated interview-questionnaire, within two domains: clarity of medical information and relationship with staff. Patient perception of health status after as compared with before the visit, and overall life satisfaction were also measured. Data on patient characteristics and healthcare characteristics were collected. Multiple linear regression analysis was used, and significance was considered at $\mathrm{p} \leq 0.05$.

Results One-third (32.8\%) of patients showed high level of overall satisfaction and $26.7 \%$ were unsatisfied, with percentage mean score of $70.36 \%$ (17.40), reflecting moderate satisfaction. After adjusting for all potential confounders, lower satisfaction with the ED visit was significantly associated with male gender $(p<0.001)$, long waiting time $(p=0.032)$ and low perceived health status compared with status at admission $(p<0.001)$. Overall life satisfaction was not a significant predictor of patient satisfaction.

Conclusions An appreciation of waiting time as the only significant modifiable risk factor of patient satisfaction is essential to improve the healthcare services, especially at emergency settings.

\section{INTRODUCTION}

Patient satisfaction is an important goal in any healthcare system. ${ }^{1}$ The quality of healthcare delivery is often assessed on the basis of patients' perception of the care. ${ }^{2}$ As patients become more knowledgeable about healthcare, assessing its quality is a major issue to improve satisfaction of patients. $^{23}$

Prior data suggests that patient satisfaction is more influenced by patient-related sociocultural, psychosocial and disease-related characteristics than by objective quality indicators of care. ${ }^{4}$ Many factors that affect patient satisfaction are related to the healthcare services and healthcare provider.

\section{Key messages}

What is already known on this subject?

- Prior studies have found that patient satisfaction in emergency care centres (ECCs) is influenced by, wait time in the ECCs, provision of information and interpersonal relations between patients and staff.

- However, the literature on patient satisfaction in Emergency Departments (EDs) is dominated by the USA and Western countries, and as social cultural values can differ, it is possible that variables affecting satisfaction are different in other countries.

\section{What might this study add?}

- In this interview study of lower acuity patients attending an ED in Saudi Arabia, the majority of patients were highly or moderately satisfied with emergency care received; specific elements in the two patient's satisfaction domains were rated poor by at least $25 \%$ of patients.

- Actual waiting time, improvement in health status after the visit, and male sex were the only independent predictors of satisfaction with emergency care. There was no association with overall life satisfaction.

While waiting time in the ED has been shown to be an important part of satisfaction, explanations of the patient's lab tests and results, condition, and, reasons for admission have been shown to have a major impact on the level of patient satisfaction. ${ }^{2}$

Literature on patient satisfaction at an ED is dominated by the USA and Western countries. ${ }^{5} 6$ As far as we are aware, no study measuring patient satisfaction with emergency care services has been carried out in the central region of Saudi Arabia. As social cultural values between countries can differ, it was appropriate to undertake this research. The aims of this study are: (i) to assess the level of patient satisfaction and its association with some sociodemographic and healthcare characteristics at emergency care centre (ECC) of King Abdulaziz Medical City, Riyadh, Saudi Arabia and (ii) to identify the predictors of patients' satisfaction.

\section{STUDY SETTING}

The study was conducted among patients presenting to ECC of KAMC, Riyadh, Saudi Arabia. 
KAMC is a major tertiary care institution, serving patients referred throughout the Kingdom of Saudi Arabia. ECC provides services for a rapidly growing patient population in all of its catchment areas, and is the largest ECC in Riyadh with a capacity of 125 beds. The centre provides urgent care services for all patients mainly trauma and critical medical cases. The centre contains trauma X-ray and Stat Lab to be ready when time becomes critical. It is divided into two main sections; adult care: (30 consultants and 34 staff physicians) and paediatric care (20 consultants and 21 staff physicians). The average number of ECC visits is about 700 patients per day with some seasonal variations.

The ECC follows the Canadian Triage and Acuity Scale guidelines ${ }^{7}$ to categorise cases on the basis of severity. Nurses assign an urgency rating according to observable physiological parameters. $^{8}$

\section{STUDY DESIGN}

This is a prospective observational study.

\section{Study subjects and sampling technique}

Adult ECC Arabic-speaking patients above 18 years who were designated triage category III and IV were the target of this study. Every eligible participant was approached by one of the research team, and the study was explained to him/her. Patients consented verbally with full understanding of their right to withdraw from the study at any time. Patients with serious physical or mental illnesses, such as terminal disease and psychosis, were excluded, as they might not be able to comprehend and complete the questionnaire. Non-Arabic speaking patients were excluded from the study, to avoid the language barrier during data collection phase. Approval of the Institutional Review Board of the Ministry of National Guard Health Affairs was obtained before conduction of the study.

Consenting patients were followed from time of arrival at the front desk of ECC to the time of discharge. A member of the research team interviewed the patient at discharge using a previously validated questionnaire, ${ }^{9}$ assessing their satisfaction with their care in the ECC and their perception of their health status at discharge as compared with arrival.

\section{Data collection}

\section{Assessment of patient satisfaction}

Patient satisfaction was assessed using the previously validated Arabic version of the Echelle de Qualité des Soins en Hospitalisation (EQS-H), ${ }^{9}$ a well-known scale that is usually used to determine inpatient satisfaction with the quality of medical and nursing care within hospitals. ${ }^{9}{ }^{10}$ Items are clinically relevant to a hospital setting. The EQS-H was allocated for this study because of its ease of administration, being short yet comprehensive, and the availability of an Arabic version that has been previously validated.

The EQS-H is a self-reported questionnaire with two domains of patient satisfaction. The 'quality of medical information' domain contains five items, and the 'relationship with staff and daily routine' domain has 10 items. Each item is rated on a fivepoint Likert scale of five responses ('poor', 'moderate', 'good', 'very good' and 'excellent'). The overall satisfaction score is the sum of the scores for each item. ${ }^{10}$ Domain scores were also calculated.

Clarity of information domain (5 questions): A series of questions were asked to identify the level of satisfaction and perception of the patient towards the clarity of information delivered by the medical staff: Clear information about the symptoms, Reason of the investigation, Result of investigation, Cause of given medication, and Side effects of those medications. The score of this domain varies from 5 to 25 points. The percentage mean score was estimated and patients were then categorized into: highly satisfied ( $\geq 80 \%$ score), moderately satisfied (60 to $<80 \%$ score), and unsatisfied $(<60 \%$ score).

Relationship with the ECC staff domain (11 questions): To evaluate the satisfaction of the participant with the system used in the department and the relationship with the medical staff: Knowing who was the treating physician, provided privacy, department services (food, dressing and cleanliness), analgesia, response of the nursing staff, organization in the section, level of understanding within the department staff, time given by the nursing staff, medical decision sharing, care and treatment in general, and improvement during hospitalization. The total score of this domain varies from 11 to 55 points. The percentage mean score was estimated and patients were then categorized into: highly satisfied ( $\geq 80 \%$ score), moderately satisfied (60 to $<80 \%$ score), and unsatisfied $(<60 \%$ score).

\section{Patients' personal and sociodemographic characteristics}

Data on patient' characteristics were collected on arrival to ED including: gender, age, residency (rural or urban), marital status (single, married, divorced or widowed), educational level (illiterate, read and write primary/intermediate/high school, higher education) and monthly income ( $<$ US\$1500 and $\geq$ US\$1500).

\section{Emergency care-related characteristics}

Data were collected to cover the following: (a) length of stay in the ED; (b) waiting time calculated as the sum of the following: (i) time of arrival to registration, (ii) time from registration until initiation of triage, (iii) triage duration and (iv) time from triage till seen by a doctor; (c) medical insurance-that is whether the patient is affiliated to and insured medically by the National Guard Health services (Patients who are eligible to National Guard healthcare services may get somehow better service being recorded in the hospital with their all previous medical history and comorbidities. Also, they must be more familiar with the hospital and staff.); (d) type of complaint-that is the main complaint that led the patient to visit the ED; (e) improvement from admission (same, little better, much better) and (v) perceived health status compared with people of the same age (better, worse, same). ${ }^{9}$ Every patient was asked "Do you feel much better, little better or same after the ED visit?" and "Do you feel better, same or worse compared to people of same age?."

\section{Overall life satisfaction}

The importance of including a single-item scale on overall life satisfaction (OLS) when studying subjective well-being was previously highlighted by Campbell et al. ${ }^{11}$ In our research, we included the question "In general, how would you rate the level of satisfaction with your life?," using an end-labelled 0-10 scale, from completely dissatisfied to completely satisfied.

A team of four research coordinators (two males and two females) were assigned, educated and trained on using the EQS-H and OLS tools to interview the targeted participants. A pilot study was applied on five patients to ensure the feasibility and comprehensiveness of the interview. Each interview took about $10-20 \mathrm{~min}$; thus an average of 10 questionnaires was completed at different times per day over two shifts (five patients per shift). Data collection was conducted between 09:00 and 20:00 hours over the 3 months of the year (JulySeptember 2011) that have the highest number of patient 
admissions, when Riyadh city is visited by people from across Saudi Arabia.

\section{Data analysis}

Sample size was determined based on the results of a prior study in which patient satisfaction was $73 \%$. We estimated we would need 359 patients, based on an expected proportion of satisfaction that varies $\pm 10 \%,{ }^{12} \alpha=0.05$ and power $=80 \%$. Each day for 3 months, the team approached 10 randomly selected patients fulfilling the inclusion criteria.

Data were entered into the SPSS software program (V.22.0). The data were cleaned, stored and validated. Descriptive statistics such as percentages, mean, median, SD and IQR were used. Analytical statistics was applied to test the association between patient satisfaction and certain demographic and healthcare characteristics. Pearson $\chi^{2}$ test and $\chi^{2}$ test for linear trend were used for categorical data, and Student's t-test, Mann-Whitney test, analysis of variance and Pearson correlation coefficient tests were used for numerical data. Multiple linear regression analysis was applied, using the stepwise method, to identify the significant predictors of patient satisfaction score, with the following variables as independent variables; gender, age, marital status (unmarried vs married), level of education (illiterate or read and write, primary or intermediate and secondary or higher education), residence (urban or rural), income (<US\$1500 vs $\geq$ US \$1500), eligibility for National Guard Health Affairs medical insurance (yes or no), waiting time (in minutes), improvement compared with admission (score of 1-same to 3-much better), perception of health status health status compared with people of the same age (score of 1 -worse to 3-better) and OLS (score of 1 to 10$)$. Significance was considered at $\mathrm{p} \leq 0.05$.

\section{RESULTS}

\section{Patients' characteristics}

A total of 390 interviews were completed for a response rate of $65 \%$ of those who consented. Reason for non-participation was that patients were being moved around in the ED and between other units such as X-ray, making it difficult to keep track of them, and hence, ask them to participate. Another reason was that the data collector, when approaching a possible participant, rapidly noticed that a patient was not suitable for participation, for example, due to distress, and refrained from asking. Non-respondent patients were not significantly different from respondent ones with regard to age and gender $(p>0.05)$ (figure 1).

As shown in table 1, mean age of participants was 36.3 (5.6) years with $46.2 \%$ females. Nearly all the patients came from urban areas (96.7\%), the majority were married (61.8\%), with monthly income of US\$1500 or more $(82.3 \%)$ and more than one-half completed their secondary education (56.6\%). Male patients were more likely to be unmarried $(p=0.041)$ and have higher monthly income $(p=0.007)$, than female patients. The majority of patients were eligible for the Saudi National Guard Health Affairs' services (85.9\%).

\section{Emergency care-related characteristics}

The most common chief complaints were abdominal pain $(25.5 \%)$, trauma $(10.5 \%)$ and shortness of breath and per vaginal bleeding (10\% each). Waiting time ranged from 5 to $300 \mathrm{~min}$, with a median of $30 \mathrm{~min}$ and an IQR of $40 \mathrm{~min}$. It was significantly shorter for female patients $(\mathrm{z}=3.13, \mathrm{p}<0.001)$. After the visit, no improvement was reported by $28.7 \%$ of patients, while $43.6 \%$ and $27.7 \%$ of patients reported little and much improvement, respectively. Females were more likely than

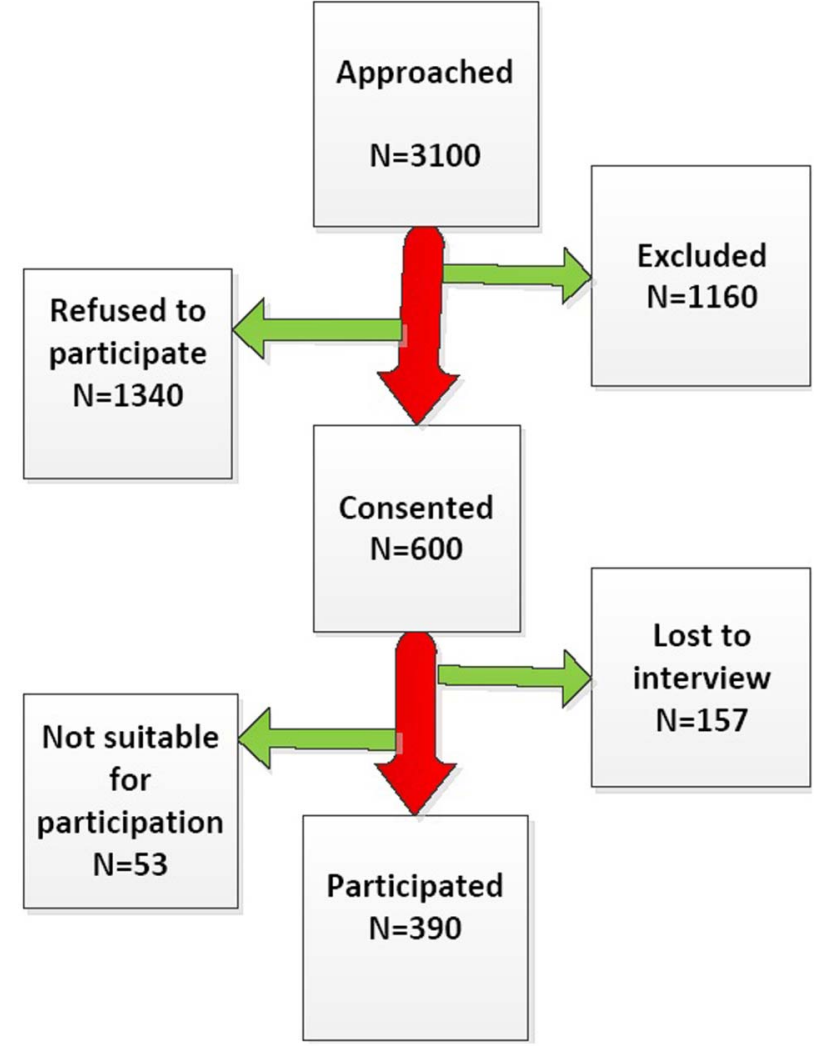

Figure 1 Flow chart of the recruitment of study participants.

males to report improvement $\left(\chi_{\mathrm{LT}}^{2}=20.90, \quad \mathrm{OR}=3.81\right.$, $\mathrm{p}<0.001)$. About half of the patients $(52.1 \%)$ perceived their health the same as other patients of same age, $29.1 \%$ better and $18.7 \%$ worse. Patients' OLS scored from 1 to 10 points, with an average score of $7.25 \pm 2.08$, reflecting moderate satisfaction (table 1).

\section{Perception/satisfaction of emergency healthcare}

Table 2 shows that poor satisfaction with the ECC was reported by $33.8 \%, 24.6 \%$ and $26.7 \%$ of patients for clarity of information, relation with staff and overall satisfaction domains, respectively. Significant gender difference was evident in favour of lower satisfaction among males in all domains $(p<0.001)$. The percentage mean score of overall satisfaction was $70.36 \pm 17.40$, reflecting moderate satisfaction. This percentage mean score was significantly higher for females than for males $(t=7.85,95 \% \mathrm{CI}$ 9.8 to $16.4, \mathrm{p}<0.001)$. Females showed significantly higher percentage mean score in all domains of satisfaction $(\mathrm{p}<0.001)$.

For the domain of clarity of information, poor satisfaction was reported for discussion of side effects (39.4\%), symptoms (12.1\%), purpose of medication $(12.1 \%)$, reason for investigation (11.3\%) and results of investigation (9.2\%) (figure 2). For relation with the staff, poor satisfaction was most commonly reported with regard to participating in medical decision-making (27.2\%) and not knowing the treating physician (17.9\%).

\section{Predictors of satisfaction of emergency care}

Figure 3 is a scatter plot showing the relationship between waiting time (in minutes) and patient satisfaction in different domains. An inverse association was shown between waiting time and level of satisfaction in all domains. As waiting time became longer, per cent mean score decreased for satisfaction of 
Table 1 Patients' characteristics and emergency care-related characteristics by gender

\begin{tabular}{|c|c|c|c|c|}
\hline Characteristics & $\begin{array}{l}\text { Female } \\
\mathrm{N}=180 \\
\mathrm{~N}(\%)\end{array}$ & $\begin{array}{l}\text { Male } \\
\mathrm{N}=210 \\
\mathrm{~N}(\%)\end{array}$ & $\begin{array}{l}\text { Total } \\
\mathrm{N}=390 \\
\mathrm{~N}(\%)\end{array}$ & Statistical sianificance \\
\hline \multicolumn{5}{|l|}{ Age group (years) } \\
\hline $18-24$ & $40(22.2)$ & $63(30.0)$ & $103(26.4)$ & \multirow[t]{4}{*}{$\chi^{2}=27.04 ; p<0.001$ * } \\
\hline $25-39$ & $84(46.7)$ & $51(24.3)$ & $135(34.6)$ & \\
\hline $40-59$ & $46(25.6)$ & $61(29.0)$ & $107(27.5)$ & \\
\hline 60 or more & $10(5.5)$ & $35(16.7)$ & 45 (11.5) & \\
\hline Mean (SD) & $37.6(5.8)$ & $34.4(4.9)$ & $36.3(5.6)$ & $t=1.85, p=0.06$ \\
\hline \multicolumn{5}{|l|}{ Residency } \\
\hline Rural & $11(6.1)$ & $2(1.0)$ & $13(3.3)$ & \multirow[t]{2}{*}{$\chi^{2}=8.005 ; p=0.005^{*}$} \\
\hline Urban & $169(93.9)$ & $208(99.0)$ & $377(96.7)$ & \\
\hline \multicolumn{5}{|l|}{ Marital status } \\
\hline Unmarried & $59(32.7)$ & $90(42.8)$ & $149(38.2)$ & \multirow[t]{2}{*}{$\chi^{2}=4.17 ; p=0.041$ * } \\
\hline Married & $121(67.3)$ & $120(57.2)$ & $241(61.8)$ & \\
\hline \multicolumn{5}{|l|}{ Education level } \\
\hline Illiterate and read and write & $28(15.6)$ & $23(11.0)$ & $51(13.1)$ & \multirow[t]{3}{*}{$\chi^{2}=8.03 ; p=0.018^{*}$} \\
\hline Primary and intermediate & $42(23.3)$ & $76(36.2)$ & $118(30.3)$ & \\
\hline Secondary and above & $110(61.1)$ & $111(52.8)$ & $221(56.6)$ & \\
\hline \multicolumn{5}{|l|}{ Monthly income } \\
\hline$<5000$ SR & $42(23.3)$ & $27(12.9)$ & $69(17.7)$ & \multirow[t]{2}{*}{$\chi^{2}=7.30 ; p=0.007^{*}$} \\
\hline$\geq 5000 S R$ & $138(76.7)$ & $183(87.1)$ & $321(82.3)$ & \\
\hline \multicolumn{5}{|l|}{ NGHA eligibility } \\
\hline Non-eligible & $14(7.8)$ & $41(19.5)$ & $55(14.1)$ & \multirow[t]{2}{*}{$\chi^{2}=11.039 ; p=0.001$ * } \\
\hline Eligible & $166(92.2)$ & $169(80.5)$ & $335(85.9)$ & \\
\hline \multicolumn{5}{|l|}{ Reason to visit ED } \\
\hline Abdominal pain & $53(29.4)$ & $46(21.9)$ & $99(25.5)$ & \multirow[t]{8}{*}{$\chi^{2}=83.02 ; p<0.001^{*}$} \\
\hline Chest pain & $7(3.9)$ & $31(14.8)$ & $38(09.7)$ & \\
\hline SOB & $17(9.4)$ & $22(10.5)$ & $39(10.0)$ & \\
\hline PV bleeding & $39(21.7)$ & $0(0)$ & $39(10.0)$ & \\
\hline Dizziness & $13(7.2)$ & $80(3.8)$ & $21(05.4)$ & \\
\hline Trauma & $5(2.8)$ & $36(17.1)$ & $41(10.5)$ & \\
\hline Headache & $7(3.9)$ & $6(2.9)$ & $13(03.3)$ & \\
\hline Others & $39(21.7)$ & $61(29.0)$ & $100(25.6)$ & \\
\hline \multicolumn{5}{|l|}{ Waiting time (in minutes) } \\
\hline Mean (SD) & $53.03(60.95)$ & $59.25(52.29)$ & $56.51(56.28)$ & \multirow[t]{2}{*}{$z=3.13, p<0.001 * \dagger$} \\
\hline Median & 30.0 & 40.0 & 30.0 & \\
\hline \multicolumn{5}{|c|}{ Improvement compared with admission } \\
\hline Same & $48(26.7)$ & $64(30.5)$ & $112(28.7)$ & \multirow[t]{3}{*}{$\chi_{\mathrm{LT}}^{2}=20.90, \mathrm{p}<0.001$ * } \\
\hline Little better & $52(28.9)$ & $118(56.2)$ & $170(43.6)$ & \\
\hline Much better & $80(44.4)$ & $28(13.3)$ & $108(27.7)$ & \\
\hline \multicolumn{5}{|c|}{ Health status compared with others } \\
\hline Worse & $45(25.0)$ & $28(13.3)$ & $73(18.7)$ & \multirow[t]{3}{*}{$\chi^{2}{ }_{L T}=1.05, p=0.3112 .608 ;$} \\
\hline Same & $78(43.3)$ & $125(59.5)$ & $203(52.1)$ & \\
\hline Better & $57(31.7)$ & $57(27.2)$ & $114(29.2)$ & \\
\hline \multicolumn{5}{|l|}{ Overall life satisfaction (scores) } \\
\hline $1-5$ & $41(22.8)$ & $41(19.5)$ & $82(21.0)$ & \multirow[t]{2}{*}{$\chi^{2}=0.618 ; p=0.432$} \\
\hline $6-10$ & $139(77.2)$ & $169(80.5)$ & $308(79.0)$ & \\
\hline Mean (SD) & $7.41(2.29)$ & $7.11(1.88)$ & $7.25(2.08)$ & $t=1.41, p=0.16$ \\
\hline
\end{tabular}

* Statistically significant.

†Mann-Whitney test was applied.

SR, Saudi Riyals; NGHA, National Guard Health Affaires; SOB, shortness of breath; PV, per-vaginal bleeding.

clarity of information $(y=71.86-0.08 * x, r=-0.21, p<0.001)$, relation with staff $(\mathrm{y}=74.09-0.05 * \mathrm{x}, \mathrm{r}=-0.16, \mathrm{p}=0.003)$ and overall patient satisfaction $(y=73.35-0.06 * x, r=-0.20$, $\mathrm{p}<0.001)$.

Figure 4 shows the relationship between perceived health improvements compared with admission and per cent mean score of EQS-H for patient satisfaction. A significant direct association was shown between the level of patients' improvement in the hospital and their percent mean scores of satisfaction. As we go from 'same' towards 'little better' and the 'much better', the corresponding percentage mean score increased significantly in clarity of information $(f=34.89, p<0.001)$, relation with staff $(\mathrm{f}=45.54, \mathrm{p}<0.001)$ and overall satisfaction ( $\mathrm{f}=54.49, \mathrm{p}<0.001)$.

Table 3 shows the results of multiple regression analysis of the percentage mean scores of satisfaction, with: gender, age, marital 
Table 2 Levels of patient satisfaction to emergency care in EQS-H domains by gender

\begin{tabular}{|c|c|c|c|c|}
\hline & $\begin{array}{l}\text { Highly satisfied } \\
\text { N (\%) }\end{array}$ & $\begin{array}{l}\text { Moderately satisfied } \\
\text { N (\%) }\end{array}$ & $\begin{array}{l}\text { Unsatisfied } \\
\mathrm{N}(\%)\end{array}$ & Percentage mean score (SD) \\
\hline \multicolumn{5}{|c|}{ Clarity of information (MI) domain } \\
\hline Male & $51(24.3)$ & 77 (36.7) & $82(39.0)$ & $63.85(18.53)$ \\
\hline Female & $89(49.4)$ & $41(22.8)$ & $50(27.8)$ & $71.73(23.85)$ \\
\hline Total & $140(35.9)$ & $118(30.3)$ & $132(33.8)$ & $67.49(21.49)$ \\
\hline$\chi^{2}=26.91 ;$ & & & & $\mathrm{t}=-3.601 ; 95 \% \mathrm{Cl}: 3.6$ to $12.2, \mathrm{p}<0.001^{*}$ \\
\hline \multicolumn{5}{|c|}{ Relation with staff (RS) domain } \\
\hline Male & $35(16.7)$ & $99(47.1)$ & $76(36.2)$ & $64.53(15.07)$ \\
\hline Female & $114(63.3)$ & $46(25.6)$ & $20(11.1)$ & $80.26(18.37)$ \\
\hline Total & $149(38.2)$ & $145(37.2)$ & 96 (24.6) & $71.79(18.40)$ \\
\hline$\chi^{2}=92.16$ & & & & $\mathrm{t}=-9.147 ; 95 \% \mathrm{Cl}: 12.3$ to $19.1, \mathrm{p}<0.001$ * \\
\hline \multicolumn{5}{|l|}{ Overall } \\
\hline Male & $32(15.2)$ & $99(47.1)$ & $79(37.7)$ & $64.28(14.15)$ \\
\hline Female & $96(53.3)$ & $59(32.8)$ & $25(13.9)$ & $77.41(18.19)$ \\
\hline Total & $128(32.8)$ & $158(40.5)$ & $104(26.7)$ & $70.36(17.40)$ \\
\hline$\chi^{2}=68.26 ;$ & & & & $\mathrm{t}=-7.847 ; 95 \% \mathrm{Cl}: 9.8$ to $16.4, \mathrm{p}<0.001^{*}$ \\
\hline
\end{tabular}

\section{Excellent $\square$ Very good $\square$ Good $\square$ Moderate $\square$ Poor}
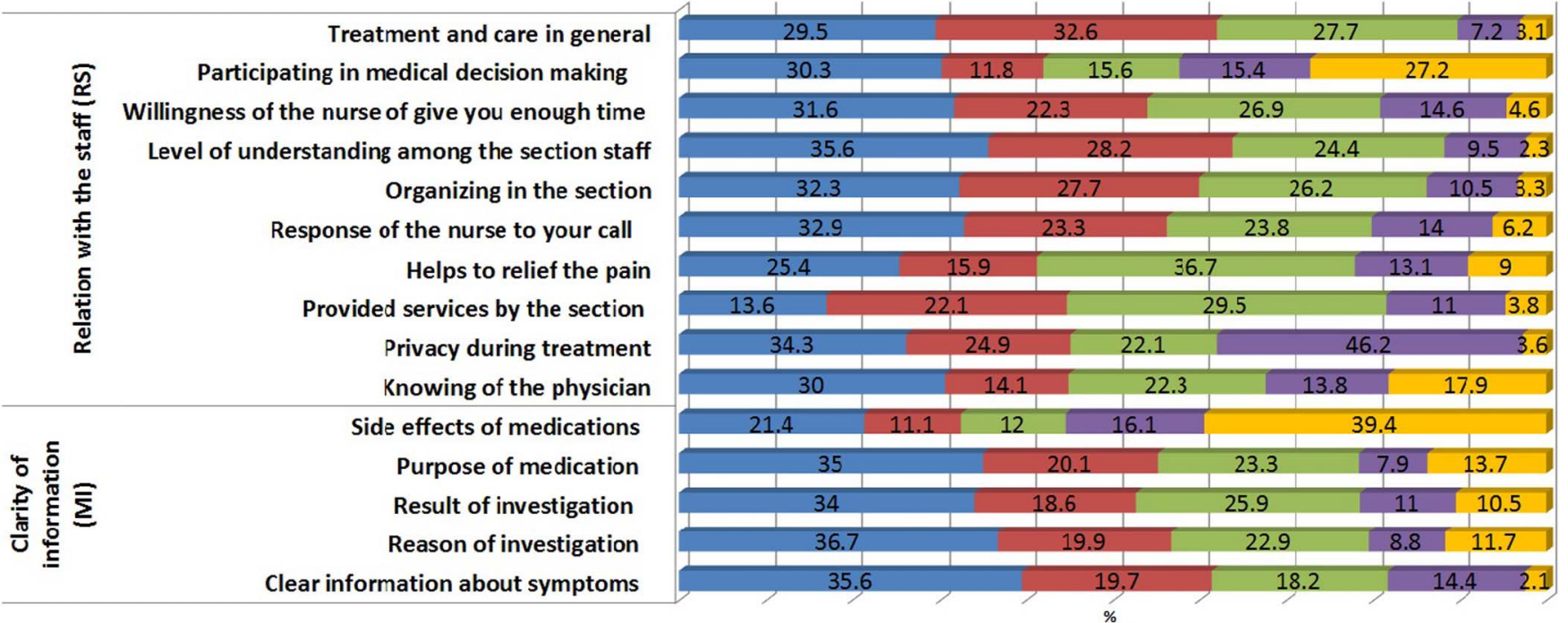

Figure 2 Responses to Echelle de Qualité des Soins en Hospitalisation domains of patient satisfaction to emergency care.

status, level of education, residence, income, eligibility for National Guard Health Affairs medical insurance, waiting time, perception of health status (score), improvement after ED visit and OLS (score) as the confounding variables. Male gender $(t=6.19, p<0.001)$, longer waiting times $(t=2.18, p<0.032)$ and lower perceived health status compared with the status at admission $(t=6.85, p<0.001)$ were the only significant predictors of lower scores of overall satisfaction. Percentage mean score of satisfaction for males was $10.14 \%$ lower than females. Gender, waiting time and improvement compared with arrival in the ED were significant predictors of satisfaction of clarity of information as well, yet waiting time was not a significant predictor of satisfaction of the relation with staff $(t=1.68, p=0.094)$.

\section{DISCUSSION}

The ECC is the first point of contact for many people who need acute health services. Our study is the first to be conducted in Saudi Arabia to determine patient satisfaction with emergency healthcare by means of the Arabic version of the EQS-H. Previous studies have evaluated patient satisfaction in Western countries, ${ }^{9} 10$ 13 ${ }^{13}$ but little is known about patient satisfaction in Arab countries, where sociocultural values are different. ${ }^{9}$ The overall level of satisfaction observed in our population (70.4\%) corresponds to moderate satisfaction, and is lower than levels reported previously. ${ }^{6} 8$ Further studies are necessary to identify the reasons behind such difference.

One of the strengths of our study is that we attempt to demonstrate the relationship between perception of emergency care and perceived health status compared with admission. Patient ratings of their health status have been reported to be better predictors of satisfaction than physician ratings. ${ }^{14}$ Our results demonstrated a significant and relationship between perceived improvement in health status and the satisfaction score, in agreement with previous results. ${ }^{9} 15$ Perceived improvement in health status represents a relief of suffering and should logically be related to higher satisfaction. However, accurate interpretations of comparative satisfaction data require consideration of the 
Figure 3 Relationship between waiting time and patient satisfaction of clarity of information (MI), relation with staff (RS) and overall satisfaction.

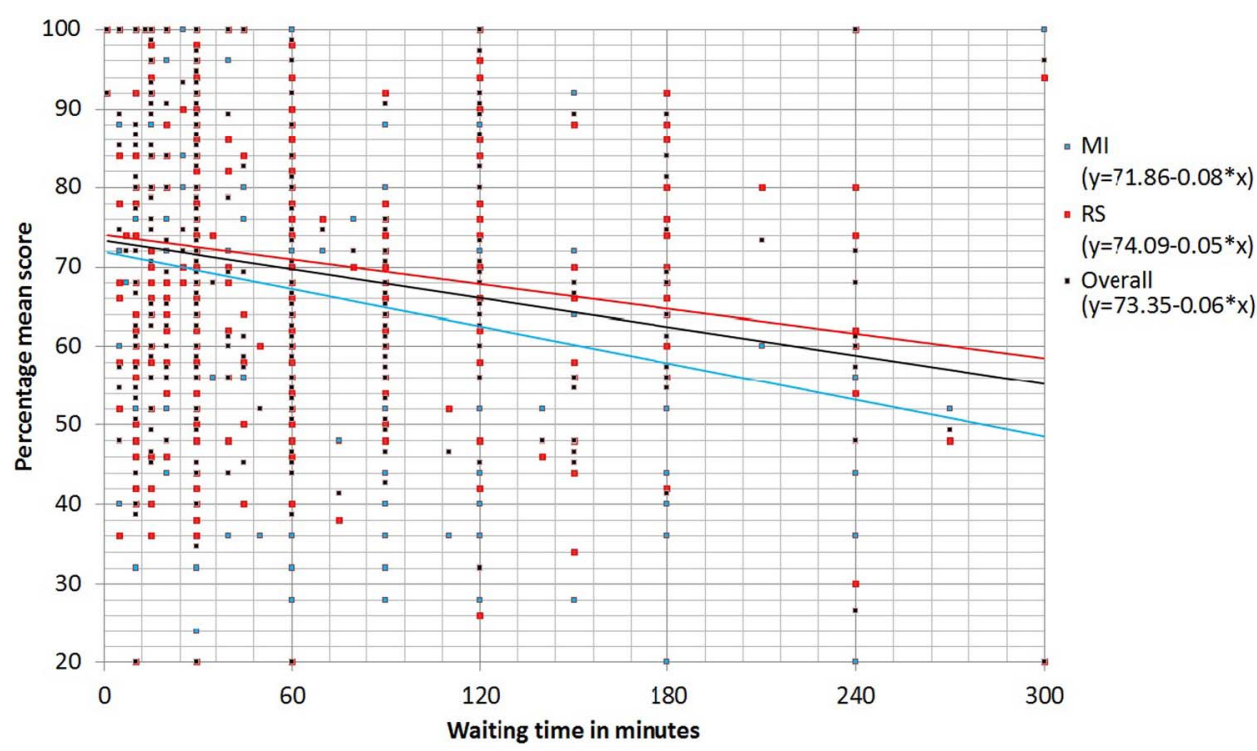

illness profile of the population samples involved. ${ }^{14}$ In the present study, the reasons for visiting the ECC included abdominal pain, shortness of breath, vaginal bleeding and dizziness, among others and our analysis could not adjust for all these variations when investigating the predictors of satisfaction.

Self-perceived health status is not usually considered important in satisfaction studies, especially when comparing different patient groups. ${ }^{16}$ In our cohort, perceived health status compared with others of the same age was not significantly associated with satisfaction score. Interestingly, patient satisfaction with emergency care also showed no association with patient satisfaction with life in general. Previous results have suggested that a high level of general satisfaction with life indicates a positive viewpoint that enables patients to be satisfied with their care. ${ }^{9}$ However, patients with high levels of satisfaction with life might also have higher expectations than those with lower levels of satisfaction with life.

Previous results have shown that the satisfaction of patients in ECCs is influenced by the provision of information, waiting

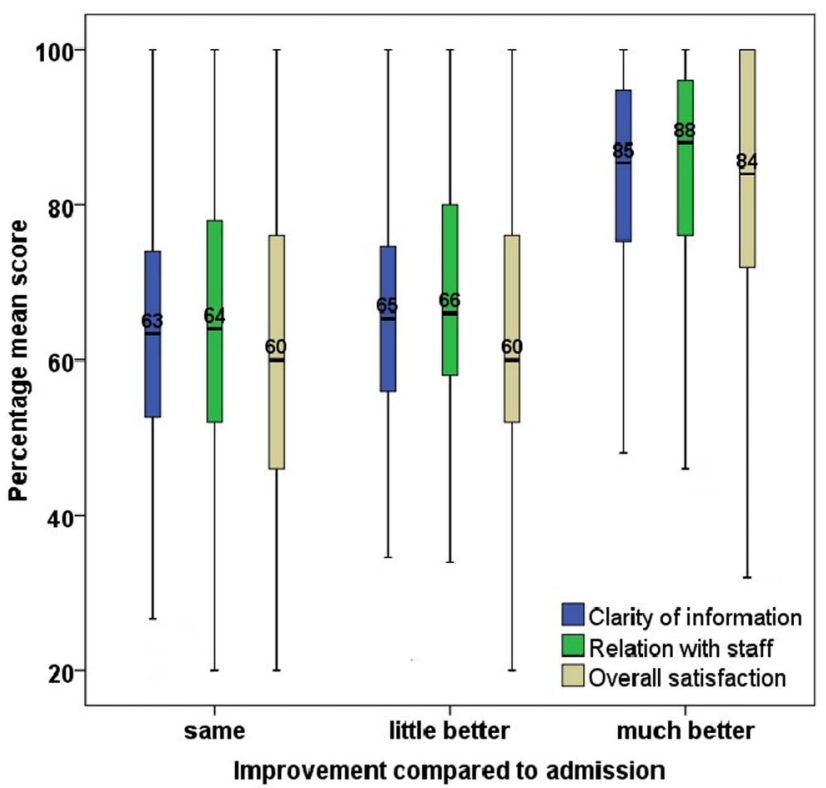

Figure 4 Relationship between perceived health improvement as compared with admission and per cent mean score of Echelle de Qualité des Soins en Hospitalisation for satisfaction. time in the ECC and interpersonal relations between patients and staff. ${ }^{17}{ }^{18}$ Evidence shows that a strong positive correlation exists between provision of information by doctors and patient satisfaction. ${ }^{19}$ In the present study, poor satisfaction with clarity of information was reported by $33.8 \%$ of patients, particularly for side effects, symptoms, purpose of medication, reason for and results of investigations. These findings are comparable with those reported in a study in Morocco by Soufi et al. ${ }^{9}$

Good interpersonal relationships can positively influence satisfaction with visits to the ECC, and can contribute to improvements in patient care and health outcomes. ${ }^{9}$ Our patient population reported poor satisfaction with regard to participation in medical decision-making (27.2\%) and being able to identify the treating physician (17.9\%). Satisfied patients are less likely to seek out a second opinion, which has implications in terms of reducing medical costs. Therefore, investment in improving physician communication and interpersonal skills can potentially result in benefits for patients' understanding of their care as well as their overall satisfaction, without changing the objective aspects of the care received. ${ }^{20}$

In our study, the satisfaction scores were higher for women than for men in both domains, which contrasts with some previous results, ${ }^{9}{ }^{15}$ but is consistent with others. ${ }^{19}$ These results might indicate that-especially in Saudi culture, where paternalism is the norm-men have greater expectations than women.

Waiting time is a key component of patient satisfaction, and significant efforts have been made to reduce ED waiting times and increase overall ED efficiency. ${ }^{21}$ The median waiting time in the present study was $30 \mathrm{~min}$ with an IQR of $40 \mathrm{~min}$. Although there are various definitions of waiting time, it was calculated from arrival at the front desk till seen by a doctor for all patients. In our study, waiting time was correlated with patient satisfaction in all domains, and was a significant predictor of satisfaction in the clarity of information domain and overall, before and after adjustment for covariates. However, the perception of waiting time may be more important to patient satisfaction than the actual length of time. ${ }^{22}{ }^{23}$ Interventions can reduce patients' perception of their waiting times. ${ }^{24}$

\section{Limitations}

This was a single-centre study, with a $65 \%$ response rate. Data were not collected overnight and this could have affected generalisability as well as given the opportunity to compare satisfaction levels at different times. While we only included lower 
Table 3 Predictors of patient satisfaction to emergency care in EQS-H domains

\begin{tabular}{|c|c|c|c|c|c|c|c|c|c|}
\hline & \multicolumn{3}{|c|}{ Clarity of information } & \multicolumn{3}{|c|}{ Relation with staff } & \multicolumn{3}{|l|}{ Overall } \\
\hline & $\beta$ (SE) & $\mathbf{t}$ & $\mathrm{p}$ Value & $\beta(\mathrm{SE})$ & $\mathbf{t}$ & $p$ Value & $\beta$ (SE) & $\mathbf{t}$ & $p$ Value \\
\hline Gender (male=1) & $-4.49(2.14)$ & 2.10 & $0.037^{*}$ & $-13.06(1.64)$ & 7.95 & $<0.001^{*}$ & $-10.14(1.64)$ & 6.19 & $<0.001$ * \\
\hline Waiting time (min) & $-0.05(0.02)$ & 2.60 & $0.010^{*}$ & $-0.03(0.02)$ & 1.68 & 0.094 & $-0.03(0.01)$ & 2.18 & $0.032^{*}$ \\
\hline Improvement compared with admission & $8.36(1.48)$ & 5.65 & $<0.001^{*}$ & $7.62(1.09)$ & 6.99 & $<0.001^{*}$ & $7.75(1.13)$ & 6.85 & $<0.001$ * \\
\hline Constant & $56.24(3.92)$ & 14.34 & $<0.001^{*}$ & $74.52(6.97)$ & 10.69 & $<0.001^{*}$ & $62.03(3.00)$ & 20.67 & $<0.001^{*}$ \\
\hline
\end{tabular}

acuity patients, this is a similar population to those interviewed in other studies in other countries. However, the finding of lower satisfaction in our study than those in Western countries could be attributed to the different measures of patient satisfaction used with different domains and different scoring systems, rather than to actual difference in the level of satisfaction. Collection of qualitative data could have generated additional interesting and important information. We were unable to account for the different disease processes that could have resulted in level of perceived improvement after the ED visit.

\section{CONCLUSION}

Our results have identified areas that could be targeted to facilitate improvement in the provision of emergency patient care. Waiting time, male gender and perceived improvement in health status were demonstrated to be independent factors predicting overall satisfaction with the ECC visit. Nevertheless, other areas of satisfaction were found that could be improved. Waiting time in the ECC is often long, and reducing actual waiting time may require substantial resources, but improving patient-physician interactions and providing patients with a greater understanding of their care process are possible alternative means to positively influence patient satisfaction with emergency visits. Practical measures could include routinely informing patients about their triage level, as well as their estimated waiting time before being seen by a doctor.

Correction notice Since this paper was first published online changes have been made to tables 1 and 2. In table 1, the characteristic 5000 SR or more for females has changed from 13 (876.7) to 138 (76.7). Under the male eligible category the number has changed to 169 (80.5). Under the education level category, a * has been added to the $p$-value. In table 2 the overall male unsatisfied percentage has changed from (37.6) to (37.7). In the second key message the text has been updated to read 'in the two patient's satisfaction domains..'

Acknowledgements This study was supported by the King Abdullah International Medical Research Center (KAIMRC), King Saud bin Abdulaziz University for Health Sciences, Riyadh, Saudi Arabia. Authors would like to thank Ms Aisha Mahfouz and Mr Ala'a Bani-Mustafa, the research coordinators at KAIMRC, for their efforts in editing and finalising the figures.

Contributors All authors contributed to the design and execution of the study and analyses. MAA and RAH were actively involved in writing the manuscript. RTA, MHA-A and ZMA collected the data and shared data analysis and interpretation. ASA and RAH commented on drafts presented to them. All authors read and approved the final manuscript.

Competing interests None declared.

Ethics approval IRB of the Ministry of Saudi National Guard Health Affairs. Provenance and peer review Not commissioned; externally peer reviewed.

Open Access This is an Open Access article distributed in accordance with the Creative Commons Attribution Non Commercial (CC BY-NC 4.0) license, which permits others to distribute, remix, adapt, build upon this work non-commercially, and license their derivative works on different terms, provided the original work is properly cited and the use is non-commercial. See: http://creativecommons.org/ licenses/by-nc/4.0/

\section{REFERENCES}

1 Tasso K, Behar-Horenstein LS, Aumiller A, et al. Assessing patient satisfaction and quality of care through observation and interview. Hosp Top 2002:80:4-10.

2 Woodring S, Polomano RC, Haack MM, et al. Development and testing patient satisfaction measure for inpatient psychiatry care. J Nurs Care Qual 2004;19:137-47.

3 Messner ER. Quality of care and patient satisfaction the improvement efforts of one emergency department. Top Emerg Med 2005;27:132-41.

4 Ameriyon A, karim Bahadori M, Meskarpour MA, et al. Patient satisfaction and its related factors within emergency care departments: a study of Iranian military hospitals. J Am Sci 2010;6;1629-35. http://www.americanscience.org

5 Quintana JM, Gonzlez N, Bilbao A, et al. Predictors of patient satisfaction with hospital health care. BMC Health Serv Res 2006;6:102.

6 Bleich SN, Ozaltin E, Murray CJL. How does satisfaction with the healthcare system relate to patient experience? Bull World Health Organ 2009;87:271-8.

7 Murray M, Bullard M, Grafstein E, for the CTAS§ and CEDIS National Working Groups. Revisions to the Canadian emergency department triage and acuity scale implementation guidelines. Can J Emerg Med 2004;6:421-7.

8 Considine J, LeVasseur SA, Villanueva E. The Australasian Triage Scale: examining emergency department nurses' performance using computer and paper scenarios. Ann Emerg Med 2004;44:516-23.

9 Soufi G, Belayachi J, Himmich $\mathrm{S}$, et al. Patient satisfaction in an acute medicine department in Morocco. BMC Health Serv Res 2010;10:149.

10 Moret L, Nguyen JM, Pillet N, et al. Improvement of psychometric properties of a scale measuring inpatient satisfaction with care: a better response rate and a reduction of the ceiling effect. BMC Health Serv Res 2007;7:197.

11 Campbell A, Converse PE, Rodgers WL. The quality of American life: perceptions, evaluations, and satisfactions. New York: Russell Sage, 1976.

12 Ekwall A, Gerdtz M, Manias E. The influence of patient acuity on satisfaction with emergency care: perspectives of family, friends and carers. J Clin Nurs 2008;17: 800-9.

13 Bos N, Sturms LM, Schrijvers AJ, et al. The Consumer Quality index (CQ-index) in an accident and emergency department: development and first evaluation. BMC Health Serv Res 2012;12:284.

14 Hall J, Feldstein M, Fretwell M, et al. Older patients' health status and satisfaction with medical care in an HMO population. Med Care 1990;28:261-9.

15 Brown AD, Sandoval GA, Levinton C, et al. Developing an efficient model to select emergency department patient satisfaction improvement strategies. Ann Emerg Med 2005;46:3-10.

16 Nguyen Thi PL, Briançon S, Empereur F, et al. Factors determining inpatient satisfaction with care. Soc Sci Med 2002;54:493-504.

17 Magaret ND, Clark TA, Warden CR, et al. Patient satisfaction in the emergency department: a survey of paediatric patients and their parents. Acad Emerg Med 2002;9:1379-88.

18 Boudreaux ED, Friedman J, Chansky ME, et al. Emergency department patient satisfaction: examining the role of acuity. Acad Emerg Med 2004;11:162-8.

19 Cleary PD. Adjusting for patient characteristics when analyzing reports from patients about hospital care. Med Care 2001;39:635-41.

20 Soremekun OA, Takayesu JK, Stephen J, et al. Framework for analyzing wait times and other factors that impact patient satisfaction in the emergency department. J Emerg Med 2011;41:686-92.

21 Viccellio P, Schneider SM, Asplin B, et al. Emergency department crowding: high-impact solutions. American College of Emergency Website. http://www.acep. org/workarea/downloadasset.aspx?id=37960

22 Travers JP, Lee FCY. Avoiding prolonged waiting time during busy periods in the emergency department: is there a role for the senior emergency physician in triage? Eur J Emerg Med 2006;13:342-8.

23 Engel KG, Heisler M, Smith DM, et al. Patient comprehension of emergency department care and instructions: are patients aware of when they do not understand? Ann Emerg Med 2009:54:454-61.

24 Katz K, Larson B, Larson R. Prescription for the waiting in line blues: entertain, enlighten and engage. Sloan Manag Rev 1991;32:44-53. 